\title{
Evaluasi Usability Human-Interface Virtual Keyboard Qwerty Berdasarkan Prinsip Ergonomi dengan Metode Focus Group Discussion
}

\author{
B Febrilliandika $^{1}$, H Oktaviani $^{2}$, L S Siregar ${ }^{3}$ \\ ${ }^{1,2,3}$ Departemen Teknik Industri, Universitas Sumatera Utara, Medan \\ Jl. Dr Mansyur No 9, Medan, 20155 \\ 1bayufebrilliandikha@gmail.com
}

Intisari - Keyboard qwerty ditemukan pada tahun 1873 dengan tujuan untuk memperlambat pengetikan pada mesin ketik manual sehingga mencegah kesalahan pengetikan dan kerusakan mesin ketik. Seiring perkembangan zaman, teknologi juga berubah. Proses pengetikan kini tidak lagi menggunakan mesin ketik tetapi menggunakan perangkat komputer salah satunya adalah handphone. Namun, bentuk layout keyboard yang umum digunakan pada handphone adalah keyboard qwerty. Bentuk keyboard ini tidak mengalami perubahan sejak pertama kali ditemukan. Keyboard qwerty dianggap tidak sesuai jika diaplikasikan di handphone karena berbeda tujuan dari penciptaan awal. Berdasarkan survei pendahuluan didapatkan hasil sebanyak 53\% responden mengaku sulit menggunakan keyboard qwerty di handphone karena bagian sudut sulit dicapai oleh ibu jari. Tujuan penelitian adalah untuk merancang sebuah interface keyboard baru secara ergonomis dengan metode focus group discussion (FGD). Indikator perbaikan layout keyboard ditandai dengan nilai usability yang lebih tinggi dibandingkan keyboard qwerty. Hasil akhir yang didapat dari proses FGD, keyboard usulan harus disesuaikan dengan dimensi antropometri panjang ibu jari. Susunan huruf juga harus disesuaikan dengan intensitas penggunaan huruf dimana huruf yang memiliki intensitas tinggi akan didekatkan. Perbandingan usability keyboard qwerty dengan keyboard usulan yang diukur melalui kuisoner SUS didapatkan kesimpulan bahwa skor usability desain keyboard usulan lebih baik yaitu sebesar 60.20 dibandingkan skor usability interface keyboard qwerty sebesar 54.16. Interpretasi akhir menunjukkan bahwa desain keyboard usulan dapat lebih diterima dan digunakan dengan nyaman oleh user.

Kata kunci - Keyboard, Usability, Kuesioner SUS, FGD

Abstract - The qwerty keyboard was invented in 1873 with the aim of slowing down typing on manual typewriters so as to prevent typing errors and typewriter crashes. Along with the times, technology also changes. The typing process is now no longer using a typewriter but using a computer, one of which is a cellphone. However, the form of keyboard layout that is commonly used on cellphones is a qwerty keyboard. The shape of this keyboard has not changed since it was first discovered. The qwerty keyboard is considered inappropriate when applied to mobile phones because it is different from the purpose of its initial creation. Based on the preliminary survey, 53\% of respondents admitted that it was difficult to use the qwerty keyboard on their cellphones because the corners were difficult to reach by their thumbs. The research objective was to design a new ergonomic keyboard interface with the focus group discussion (FGD) method. The keyboard layout improvement indicator is indicated by a higher usability value than a qwerty keyboard. The final result obtained from the FGD process, the proposed keyboard must be adjusted to the anthropometric dimensions of the length of the thumb. The arrangement of letters must also be adjusted to the intensity of the use of letters where letters that have high intensity will be brought closer. Comparison of the usability of the qwerty keyboard and the proposed keyboard as measured by the SUS questionnaire, it is concluded that the proposed keyboard design usability score is better at 60.20 compared to the usability score of the qwerty keyboard interface of 54.16. The final interpretation shows that the proposed keyboard design can be more accepted and used comfortably by the user.

Keywords - Keyboard, Usability, SUS Questionnaire, FGD 


\section{PENDAHULUAN}

Keyboard qwerty dibuat pertama kali pada tahun 1873 untuk keperluan mesin ketik. Awalnya keyboard qwerty dibuat untuk mengurangi kecepatan pengetikan sehingga menghindari kesalahan pengetikan pada mesin ketik. Saat ini hampir semua komputer menggunakan keyboard jenis qwerty termasuk pada perangkat handphone [4]. Layout yang digunakan sama dengan sejak pertama kali keyboard ini ditemukan. Keyboard qwerty dianggap tidak sesuai jika diaplikasikan di handphone karena berbeda tujuan dari penciptaan awal.

Beberapa penelitian terdahulu yang dilakukan untuk melakukan perancangan keyboard adalah penelitian August Dvorak pada 1936. Pada Keyboard ini gerakan tangan harus dilakukan secara bergantian dari tangan kiri ke tangan kanan lalu kembali ke tangan kiri. Penelitian lain adalah penelitian Workman pada 2010. Perancangan keyboard ini memiliki keunggulan yaitu perpindahan dari tangan kanan ke tangan kiri yang minimum. Namun dari penelitian diatas belum mempertimbangkan perancangan keyboard yang sesuai dengan ukuran antropometri tubuh ukuran Ibu Jari. Selain itu, juga belum mempertimbangkan proses pengetikan yang dapat dilakukan oleh satu jari yang biasa dilakukan pada handphone. Oleh karena itu penelitian ini dilakukan untuk merancang layout keyboard sesuai prinsip ergonomi dalam hal ini adalah antropometri tubuh.

Berdasarkan survei pendahuluan didapat bahwa $53 \%$ responden mengaku sulit menggunakan keyboard qwerty di handphone karena bagian sudut sulit dicapai oleh ibu jari. Oleh karena itu penelitian ini bertujuan untuk merancang sebuah interface keyboard secara ergonomis dengan usability yang lebih tinggi dibandingkan keyboard qwerty dengan metode focus group discussion (FGD).

Ergonomi adalah ilmu yang membahas interaksi antara manusia dengan peralatan atau produk dan lingkungan kerjanya. Prinsip-prinsip ergonomi diperlukan dalam melakukan sebuah perancangan teknologi agar dapat digunakan dengan lebih nyaman. Penyesuaian desain dan sistem kerja dengan kemampuan dan keterbatasan manusia (fitting the job to the man) adalah hal yang menjadi prioritas dalam bidang ergonomi. Oleh karena itu perancangan layout keyboard juga harus disesuaikan dengan keterbatasan jari-jari manusia.

Antropometri merupakan salah satu bidang kajian ergonomi yang berkaitan dengan ukuran - ukuran tubuh manusia secara alamiah. Perancangan layout keyboard harus disesuaikan dengan ukuran jari manusia agar semua fitur dapat dijangkau dan digunakan dengan baik.

Usability adalah ukuran sejauh mana suatu produk dapat digunakan secara efektif dan efisien untuk mencapai kepuasan pengguna (Rahadi, 2014). Pengukuran usability terdiri atas lima aspek yaitu kemudahan (learnability), efisiensi (efficiency), kemudahan diingat (memorability), kesalahan (error), dan kepuasan (satisfaction). Semakin tinggi skor usability mengindikasikan semakin terpenuhi kepuasaan pengguna. Data usability dikumpulkan dengan kuisoner. SUS (System Usability Scale) adalah kuisoner yang dapat digunakan untuk menggambarkan persepsi subjektif pengguna terhadap usability sebuah produk .

Metode Focus Group Discussion adalah suatu diskusi terstruktur yang dipandu oleh seorang fasilitator untuk menghasilkan data kualitatif tentang suatu topik permasalahan (Masadeh, 2012). Selama diskusi berlangsung moderator harus fokus mengarahkan pada tujuan diskusi, sehingga diskusi tetap berada pada arah yang sesuai.

\section{METODOLOGI}

\section{A. Populasi dan Sampel}

Populasi penelitian ini adalah mahasiswa Teknik Industri USU berjumlah 114 orang. Populasi ini dipilih karena masuk kedalam kategori dewasa yang merupakan kategori sangat sering menggunakan smartphone. Penentuan sampel dilakukan dengan teknik insidensial sampling dimana setiap populasi yang ditemui akan dijadikan sampel. Perhitungan jumlah sampel dilakukan dengan rumus Slovin dengan error margin 5\%. 
$\mathrm{n}=\frac{\mathrm{N}}{1+\mathrm{Ne}^{2}}$

$\mathrm{n}=\frac{114}{1+114(0.05)^{2}}$
$\mathrm{n}=89$

Berdasarkan perhitungan didapat bahwa jumlah sampel pada penelitian sebesar 89 orang.

\section{B. Pengumpulan Data}

Data yang dikumpulkan adalah persepsi sampel terhadap usability keyboard qwerty aktual dengan keyboard usulan dengan menggunakan kuisoner SUS. Adapun daftar pertanyaan pada kuisoner SUS dapat dilihat pada Tabel 1. Masing-masing responden memberikan jawaban pada setiap pertanyaan dengan menggunakan skala likert 1-5.

Tabel 1. Item Pertanyaan pada Kuisoner SUS

\begin{tabular}{|l|l|}
\hline No & \multicolumn{1}{|c|}{ Pertanyaan } \\
\hline R1 & $\begin{array}{l}\text { Saya berpikir akan menggunakan sistem ini } \\
\text { lagi. }\end{array}$ \\
\hline R2 & $\begin{array}{l}\text { Saya merasa sistem ini rumit untuk } \\
\text { digunakan. }\end{array}$ \\
\hline R3 & Saya merasa sistem ini mudah digunakan. \\
\hline R4 & $\begin{array}{l}\text { Saya membutuhkan bantuan dari orang lain } \\
\text { atau teknisi dalam menggunakan sistem ini. }\end{array}$ \\
\hline R5 & $\begin{array}{l}\text { Saya merasa fitur-fitur sistem ini berjalan } \\
\text { dengan semestinya. }\end{array}$ \\
\hline R6 & $\begin{array}{l}\text { Saya merasa ada banyak hal yang tidak } \\
\text { konsisten (tidak serasi pada sistem ini). }\end{array}$ \\
\hline R7 & $\begin{array}{l}\text { Saya merasa orang lain akan memahami cara } \\
\text { menggunakan sistem ini dengan cepat. }\end{array}$ \\
\hline R8 & Saya merasa sistem ini membingungkan. \\
\hline R9 & $\begin{array}{l}\text { Saya merasa tidak ada hambatan dalam } \\
\text { menggunakan sistem ini. }\end{array}$ \\
\hline R10 & $\begin{array}{l}\text { Saya perlu membiasakan diri terlebih dahulu } \\
\text { sebelum menggunakan sistem ini. }\end{array}$ \\
\hline
\end{tabular}

\section{Pengolahan Data Usability}

Data yang didapatkan melalui kuisoner SUS diolah untuk didapatkan nilai skor SUS. Rumus perhitungan skor SUS adalah sebagai berikut.

Skor SUS $=\sum\left(\mathrm{R}_{\text {ganji }}-1\right)+\sum\left(5-\mathrm{R}_{\text {genap }}\right)$

Usability $=\frac{\sum \text { SkorSUS } \times 2.5}{\mathrm{n}}$
$\mathrm{R}$ adalah daftar pertanyaan yang terdiri atas pertanyaan bernomor ganjil atau genap. Analisis skor usability dilakukan untuk melihat nilai acceptable ranges, Grade Scale, dan Adjective Ratings.

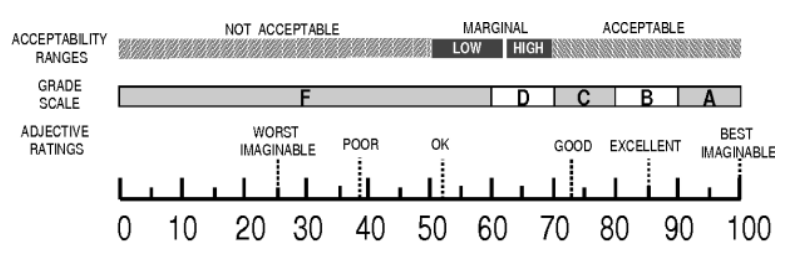

Gbr. 1 Skor SUS

\section{Pelaksanaan Focus Group Discussion (FGD)}

Pelaksanaan FGD dilakukan untuk mencari desain usulan keyboard berdasarkan permasalahan yang ada. Adapun urutan pembahasan dalam FGD adalah sebagai berikut [6].

1. Identifikasi masalah terkait dengan usability desain aktual

2. Solusi dan saran perbaikan desain berdasarkan permasalahan yang telah teridentifikasi.

3. Prioritas permasalahan yang akan diselesaikan.

\section{E. Pengolahan Data Antropometri Tubuh}

Data hasil pengukuran antropometri tubuh dilakukan uji normalitas data Lilliefors dengan software SPSS. Kemudian dilakukan uji keseragaman data. Penentuan batas atas dan batas bawah dalam uji keseragaman data dilakukan dengan rumus berikut.

$$
\begin{aligned}
& \mathrm{BKA}=\mathrm{Xbar}+\mathrm{k} \sigma \\
& \mathrm{BKB}=\mathrm{Xbar}-\mathrm{k} \sigma
\end{aligned}
$$

Kemudian dilakukan uji kecukupan data untuk menentukan apakah data yang diambil sudah cukup mewakilkan populasi. Jika nilai $\mathrm{N}^{\prime}<\mathrm{N}$, data dianggap cukup dan tidak perlu dilakukan pengambilan data kembali [5]. Rumus uji kecukupan data adalah sebagai berikut. 
$\mathrm{N}^{\prime}=\frac{\frac{k}{s} \sqrt{\mathrm{N} \sum \mathrm{X}^{2}-\left(\sum X\right)^{2}}}{\sum \mathrm{X}}$

Perhitungan dimensi akhir dilakukan dengan persentil 10. Persentil ini dipilih agar dimensi ibu jari terkecil masih dapat menggunakan keyboard dengan nyaman. Perhitungan dimensi keyboard dilakukan dengan rumus berikut.

$$
\mathrm{L}=\mathrm{X}_{\mathrm{bar}}-1.28 \alpha
$$

Nilai $\mathrm{X}_{\text {bar }}$ adalah panjang ibu jari rata-rata sampel yang berjumlah 89 orang. Nilai $\alpha$ adalah standard deviasi dari pengukuran panjang ibu jari sampel. Nilai 1.28 adalah ketetapan yang didapatkan dari persentil 10 . Hasil akhir berupa nilai L akan menjadi dimensi panjang dan lebar keyboard usulan. Alur penelitian dapat dilihat pada Gambar 2.

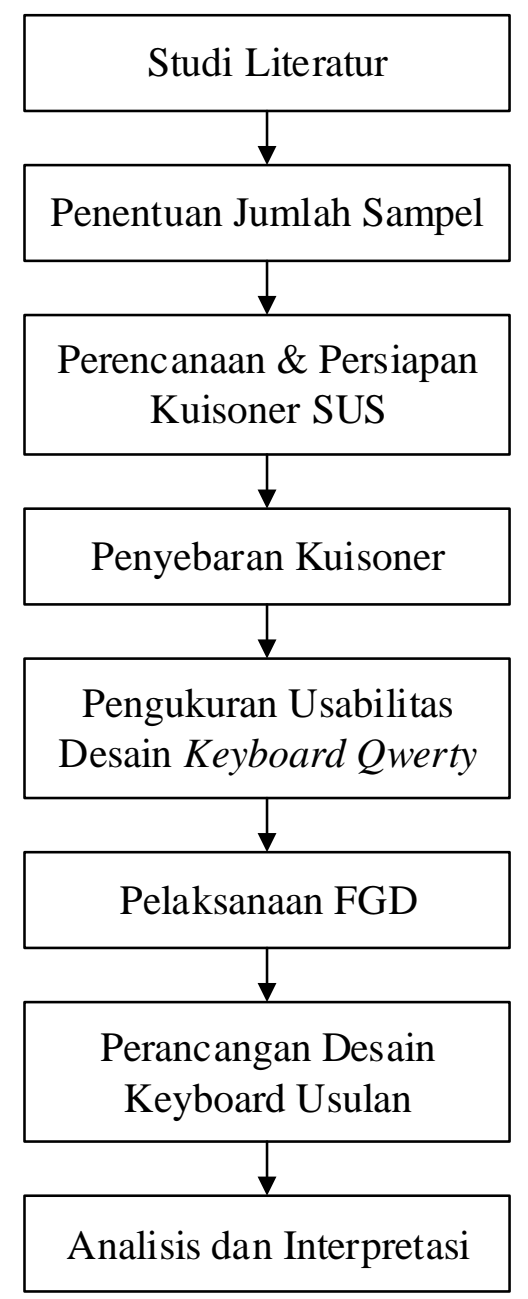

Gbr. 2 Alur Penelitian
Berdasarkan gambar diatas, penelitian diawali dengan melakukan studi literatur yang berkaitan dengan permasalahan yang dikaji. Kemudian dilakukan penentuan sampel dalam penelitian sebagai penilai tingkat usability keyboard qwerty. Permasalahan dan solusi dalam proses penggunaan keyboard qwerty diidentifikasi dengan metode focus group discussion. Solusi yang ditemukan menjadi dasar dalam perancangan keyboard usulan. Selanjutnya dilakukan penilaian tingkat usability keyboard usulan yang telah dirancang. Tahap akhir dilakukan analisa dan interpretasi untuk menentukan kesimpulan dari rancangan keyboard usulan.

\section{HASIL DAN PEMBAHASAN}

\section{A. Perhitungan Usability Desain Keyboard Qwerty}

Perhitungan usability keyboard qwerty dilakukan dengan menggunakan kuisoner SUS. Adapun rekapitulasi nilai Skor SUS dapat dilihat pada perhitungan dibawah.

$$
\begin{array}{ll}
\text { Usability } & =(1928 \times 2.5) / 89 \\
\text { Usability } & =54.16
\end{array}
$$

Berdasarkan perhitungan, nilai usability keyboard Qwerty adalah sebesar 54.19.

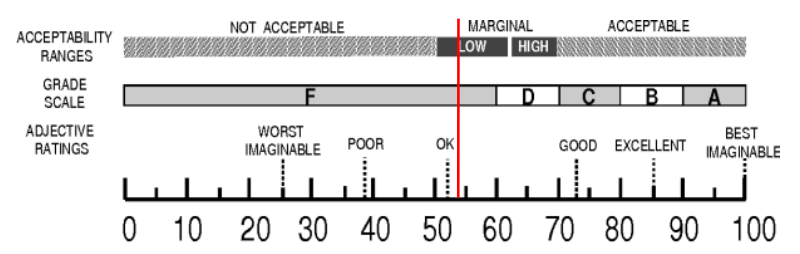

Gbr. 3 Skor SUS Keyboard Qwerty

Berdasarkan perhitungan, Acceptability Ranges masuk kedalam kaetgori low, Grade Scale terkategori F, dan Adjective Rating terkategori $O k$. 
Tabel 2. Penilaian Skor SUS Keyboard Qwerty

\begin{tabular}{|c|c|c|c|c|c|}
\hline Resp & Skor & Resp & Skor & Resp & Skor \\
\hline 1 & 22 & 31 & 26 & 61 & 22 \\
\hline 2 & 19 & 32 & 21 & 62 & 20 \\
\hline 3 & 19 & 33 & 21 & 63 & 14 \\
\hline 4 & 17 & 34 & 30 & 64 & 20 \\
\hline 5 & 23 & 35 & 23 & 65 & 16 \\
\hline 6 & 21 & 36 & 20 & 66 & 21 \\
\hline 7 & 12 & 37 & 25 & 67 & 18 \\
\hline 8 & 18 & 38 & 18 & 68 & 22 \\
\hline 9 & 19 & 39 & 23 & 69 & 24 \\
\hline 10 & 23 & 40 & 26 & 70 & 11 \\
\hline 11 & 0 & 41 & 28 & 71 & 22 \\
\hline 12 & 0 & 42 & 23 & 72 & 28 \\
\hline 13 & 25 & 43 & 22 & 73 & 14 \\
\hline 14 & 25 & 44 & 23 & 74 & 23 \\
\hline 15 & 25 & 45 & 32 & 75 & 29 \\
\hline 16 & 29 & 46 & 18 & 76 & 34 \\
\hline 17 & 28 & 47 & 20 & 77 & 25 \\
\hline 18 & 17 & 48 & 28 & 78 & 19 \\
\hline 19 & 25 & 49 & 13 & 79 & 20 \\
\hline 20 & 23 & 50 & 26 & 80 & 21 \\
\hline 21 & 36 & 51 & 17 & 81 & 22 \\
\hline 22 & 16 & 52 & 26 & 82 & 21 \\
\hline 23 & 16 & 53 & 21 & 83 & 17 \\
\hline 24 & 21 & 54 & 23 & 84 & 31 \\
\hline 25 & 20 & 55 & 24 & 85 & 26 \\
\hline 26 & 27 & 56 & 17 & 86 & 20 \\
\hline 27 & 27 & 57 & 24 & 87 & 23 \\
\hline 28 & 25 & 58 & 20 & 88 & 22 \\
\hline 29 & 26 & 59 & 17 & 89 & 19 \\
\hline 30 & 25 & 60 & 20 & $\sum$ & 1928 \\
\hline & & & & & \\
\hline
\end{tabular}

\section{B. Pelaksanaan Focus Group Discussion}

Tahap pelaksanaan FGD dilakukan sampel Mahasiswa Teknik Industri USU. Terdapat tiga tahap sebagai berikut.

\section{1) Identifikasi Permasalahan pada Keyboard Qwerty}

Permasalahan yang diidentifikasi dari anggota pelaksanaan FGD dikelompokkan kedalam empat ketegori usability dalam kuisoner SUS yang dapat dilihat pada Tabel 3.

2) Identifikasi Solusi dan Saran Perbaikan.

Beberapa masukan dari anggota FGD berhasil diidentifikasi. Beberapa masukan bertujuan untuk meningkatkan kepuasan pengguna, sehingga tidak ada keharusan untuk mengakomodir semua masukan dalam desain usulan. Masukan yang diperoleh adalah sebagai berikut.

a. Penyesuaian Dimensi Keyboard dengan Antropometri Ibu Jari. Penyesuaian dimensi keyboard dilakukan agar bagian terujung keyboard masih dapat dijangkau dengan mudah oleh ibu jari ketika keyboard digunakan untuk mengetik dengan satu jari.

b. Perluasan Ukuran Kotak MasingMasing Huruf.

Perluasan ini dilakukan untuk menghindari kesalahan yang terjadi saat menekan huruf akibat tersentuhnya bagian jari dengan huruf yang ada disisi huruf yang dimaksud.

c. Penyesuaian Susunan Huruf Berdasarkan Intensitas Penggunaan.

Penyesuaian susunan huruf didasarkan pada intensitas penggunaan. Huruf dengan intensitas tinggi saling didekatkan untuk meminimalisir pergerakan ibu jari serta aktivitas kegiatan mencari huruf.

d. Penyesuaian Susunan Huruf Berdasarkan Urutan Abjad A-Z.

Penyesuaian susunan huruf berdasarkan abjad dilakukan agar user mudah menemukan huruf yang akan digunakan sehingga mengurangi aktivitas mencari. User akan lebih mudah menemukan huruf hanya dengan mengingat abjad A ke Z.

Tabel 3. Identifikasi Masalah Keyboard Qwerty

\begin{tabular}{|l|l|}
\hline \multicolumn{1}{|c|}{ Kategori } & \multicolumn{2}{|c|}{ Permasalahan } \\
\hline $\begin{array}{l}\text { Kemudahan } \\
\text { (learnability) }\end{array}$ & $\begin{array}{l}\bullet \text { Tombol bagian ujung sulit } \\
\text { dijangkau } \\
\text { Huruf A yang sangat sering } \\
\text { digunakan terletak dibagian } \\
\text { paling ujung dan sulit dijangkau }\end{array}$ \\
\hline $\begin{array}{l}\text { Efisiensi } \\
\text { (efficiency) }\end{array}$ & $\begin{array}{l}\text { Huruf-huruf yang sering dipakai } \\
\text { letaknya berpisah }\end{array}$ \\
\hline $\begin{array}{l}\text { Kemudahan } \\
\text { Diingat } \\
\text { (memorability) }\end{array}$ & $\begin{array}{l}\text { Susunan huruf acak dan tidak } \\
\text { berurut }\end{array}$ \\
\hline $\begin{array}{l}\text { Kesalahan } \\
\text { (Error) }\end{array}$ & $\begin{array}{l}\text { Sering terjadi salah menekan } \\
\text { tombol }\end{array}$ \\
\hline $\begin{array}{l}\text { Kepuasan } \\
\text { (satisfaction) })\end{array}$ & $\begin{array}{l}\text { Sangat sulit digunakan dengan } \\
\text { satu jari sehingga perlu } \\
\text { menggunakan kedua tangan } \\
\text { untuk mengetik }\end{array}$ \\
\hline
\end{tabular}


3. Identifikasi Prioritas Masalah yang akan Diselesaikan

Perbaikan yang akan dilakukan diprioritaskan dengan mempertimbangkan masukan peserta FGD. Pada tahap ini dipilih dua solusi yang dianggap feasible untuk diaplikasikan dan dapat menyelesaikan permasalahan yang ada. Ide penyelesaian yang dipilih adalah penyesuaian dimensi keyboard dengan antropometri ibu jari dan penyesuaian susunan huruf berdasarkan intensitas penggunaan.

\section{Perancangan Desain Usulan}

Berdasarkan hasil pelaksanaan FGD terdapat dua prioritas permasalahan yang akan diselesaikan yaitupermasalahan ergonomi yang berkaitan dengan dimensi layout keyboard dan permasalahan susunan huruf.

1) Penentuan Dimensi Desain Usulan

Penentuan dimensi desain usulan dilakukan dengan memperhitungkan antropometri panjang ibu jari sampel. Data panjang ibu jari sampel dapat dilihat pada tabel 4.

Kemudian dilakukan uji normalitas data, uji keseragaman data, dan uji kecukupan data. Uji tersebut dilakukan dengan Software SPSS Hasil uji tersebut dapat dilihat pada Tabel 5.

Berdasarkan pengujian, didapatkan bahwa data berdistribusi normal, data seragam, dan data cukup sehingga data dapat digunakan untuk menentukan dimensi panjang ibu jari. Selanjutnya dilakukan perhitungan dimensi keyboard yang sesuai dengan panjang ibu jari dengan persentil 10.

$$
\begin{array}{ll}
\mathrm{L} & =5.78-1.28(0.71)=4.90 \mathrm{~cm} \\
\mathrm{~L} & =4.90 \mathrm{~cm}
\end{array}
$$

Berdasarkan perhitungan didapatkan bahwa dimensi panjang keyboard yang ergonomis sesuai dengan data antropometri panjang ibu jari manusia adalah sepanjang $4.90 \mathrm{~cm}$.
Tabel 4. Dimensi Panjang Ibu Jari Sampel

\begin{tabular}{|c|c|c|c|c|c|}
\hline Resp & $\mathbf{L}(\mathbf{c m})$ & Resp & $\mathbf{L}(\mathbf{c m})$ & Resp & $\mathbf{L}(\mathbf{c m})$ \\
\hline 1 & 6.8 & 31 & 5.8 & 61 & 5 \\
\hline 2 & 6.4 & 32 & 5.8 & 62 & 4.8 \\
\hline 3 & 6.4 & 33 & 4.7 & 63 & 5.5 \\
\hline 4 & 7 & 34 & 7.1 & 64 & 5.9 \\
\hline 5 & 6.5 & 35 & 6.5 & 65 & 6.2 \\
\hline 6 & 6.2 & 36 & 6.1 & 66 & 5.6 \\
\hline 7 & 6.9 & 37 & 5 & 67 & 7 \\
\hline 8 & 5.2 & 38 & 6.2 & 68 & 4.8 \\
\hline 9 & 4.5 & 39 & 6.3 & 69 & 5.6 \\
\hline 10 & 5 & 40 & 6.4 & 70 & 6.3 \\
\hline 11 & 4.9 & 41 & 6.2 & 71 & 4.9 \\
\hline 12 & 5.3 & 42 & 4.9 & 72 & 6 \\
\hline 13 & 6 & 43 & 5.5 & 73 & 6.1 \\
\hline 14 & 4.6 & 44 & 6 & 74 & 6 \\
\hline 15 & 4.8 & 45 & 5.8 & 75 & 7 \\
\hline 16 & 6.8 & 46 & 4.6 & 76 & 6 \\
\hline 17 & 6.3 & 47 & 5.5 & 77 & 5.5 \\
\hline 18 & 6.2 & 48 & 5.8 & 78 & 5 \\
\hline 19 & 5 & 49 & 5.5 & 79 & 5.8 \\
\hline 20 & 4.4 & 50 & 6.9 & 80 & 5 \\
\hline 21 & 6.7 & 51 & 6.3 & 81 & 5.4 \\
\hline 22 & 5.3 & 52 & 5 & 82 & 5.5 \\
\hline 23 & 6.5 & 53 & 5.5 & 83 & 6 \\
\hline 24 & 5.9 & 54 & 5.9 & 84 & 4.4 \\
\hline 25 & 5.2 & 55 & 5.5 & 85 & 6.5 \\
\hline 26 & 5.6 & 56 & 5.3 & 86 & 6 \\
\hline 27 & 6.1 & 57 & 5 & 87 & 7 \\
\hline 28 & 6.1 & 58 & 6.6 & 88 & 5.9 \\
\hline 29 & 6.1 & 59 & 5.1 & 89 & 7 \\
\hline 30 & 5.9 & 60 & 6.2 & $X_{\text {bar }}$ & 5.78 \\
\hline & & & & & \\
\hline
\end{tabular}

Tabel 5. Pengujian Data Antropometri Tubuh

\begin{tabular}{|c|c|c|}
\hline Uji & Parameter & Keterangan \\
\hline $\begin{array}{c}\text { Normalitas } \\
\text { Data } \\
\text { Lilliefors }\end{array}$ & Sig $=0.053$ & $\begin{array}{c}\text { Sig }>0.05 \\
\text { (Distribusi } \\
\text { Normal) }\end{array}$ \\
\hline $\begin{array}{c}\text { Uji } \\
\text { Keseragaman } \\
\text { Data }\end{array}$ & $\mathrm{BKA}=7.19$ & $\begin{array}{c}\text { X Max }=7.1 \\
\text { X Min }=4.4 \\
\text { (Data Seragam) }\end{array}$ \\
\hline $\begin{array}{c}\text { Uji } \\
\text { Kecukupan } \\
\text { Data }\end{array}$ & $\mathrm{N}^{\prime}=24$ & $\begin{array}{c}\mathrm{N}=89 \\
\text { (Data Cukup) }\end{array}$ \\
\hline
\end{tabular}

2) Penentuan Susunan Huruf.

Susunan huruf disusun berdasarkan intensitas penggunaannya dalam Bahasa Indonesia. Intensitas penggunaan huruf didasarkan pada penelitian [3]. 


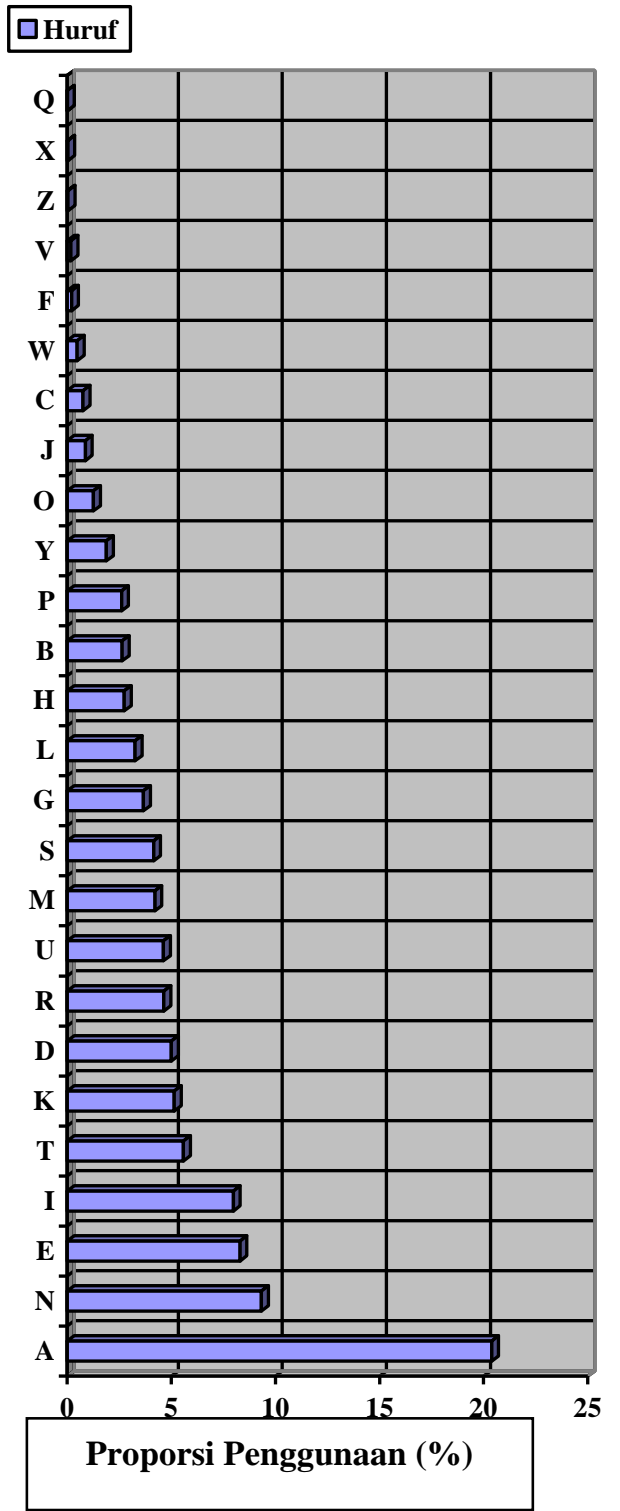

Gbr. 4 Intensitas Penggunaan Huruf dalam Bahasa Indonesia

Huruf yang paling sering digunakan diletakkan di bagian terluar keyboard agar jari tetap lurus dalam meraihnya tanpa perlu ditekuk.

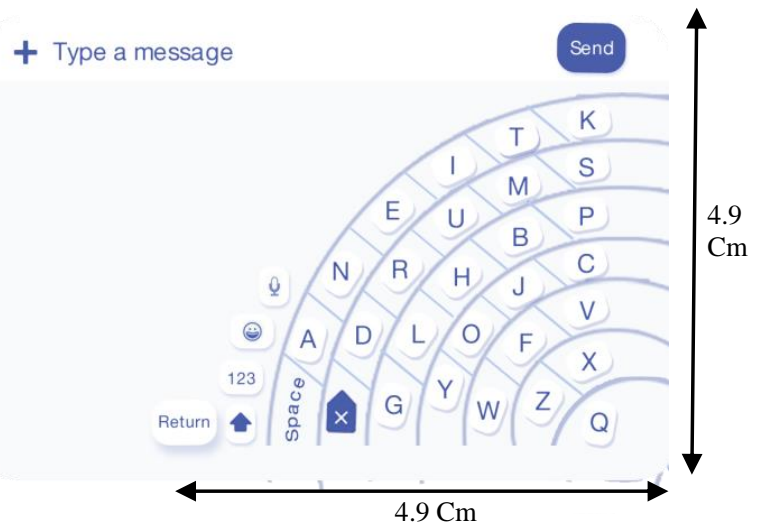

Gbr. 5 Tampilan Layout Keyboard Usulan
Adapun rekapitulasi nilai Skor SUS dapat dilihat pada perhitungan dibawah.

Tabel 6. Penilaian Skor SUS

\begin{tabular}{|c|c|c|c|c|c|}
\hline Resp & Skor & Resp & Skor & Resp & Skor \\
\hline 1 & 26 & 31 & 16 & 61 & 21 \\
\hline 2 & 36 & 32 & 22 & 62 & 20 \\
\hline 3 & 25 & 33 & 22 & 63 & 19 \\
\hline 4 & 31 & 34 & 21 & 64 & 23 \\
\hline 5 & 24 & 35 & 25 & 65 & 19 \\
\hline 6 & 26 & 36 & 25 & 66 & 23 \\
\hline 7 & 40 & 37 & 23 & 67 & 27 \\
\hline 8 & 19 & 38 & 26 & 68 & 24 \\
\hline 9 & 24 & 39 & 31 & 69 & 23 \\
\hline 10 & 25 & 40 & 25 & 70 & 34 \\
\hline 11 & 40 & 41 & 17 & 71 & 24 \\
\hline 12 & 40 & 42 & 21 & 72 & 21 \\
\hline 13 & 20 & 43 & 27 & 73 & 27 \\
\hline 14 & 19 & 44 & 17 & 74 & 21 \\
\hline 15 & 20 & 45 & 21 & 75 & 13 \\
\hline 16 & 17 & 46 & 30 & 76 & 17 \\
\hline 17 & 19 & 47 & 19 & 77 & 24 \\
\hline 18 & 21 & 48 & 24 & 78 & 17 \\
\hline 19 & 25 & 49 & 25 & 79 & 26 \\
\hline 20 & 23 & 50 & 21 & 80 & 25 \\
\hline 21 & 21 & 51 & 24 & 81 & 30 \\
\hline 22 & 15 & 52 & 19 & 82 & 23 \\
\hline 23 & 27 & 53 & 31 & 83 & 23 \\
\hline 24 & 21 & 54 & 31 & 84 & 26 \\
\hline 25 & 21 & 55 & 22 & 85 & 33 \\
\hline 26 & 27 & 56 & 23 & 86 & 24 \\
\hline 27 & 27 & 57 & 15 & 87 & 26 \\
\hline 28 & 31 & 58 & 25 & 88 & 25 \\
\hline 29 & 19 & 59 & 27 & 89 & 24 \\
\hline 30 & 33 & 60 & 24 & 5 & 2143 \\
\hline
\end{tabular}

$$
\begin{array}{ll}
\text { Usability } & =(2143 \times 2.5) / 89 \\
\text { Usability } & =60.20
\end{array}
$$

Berdasarkan perhitungan, nilai usability keyboard Qwerty adalah sebesar 60.20.

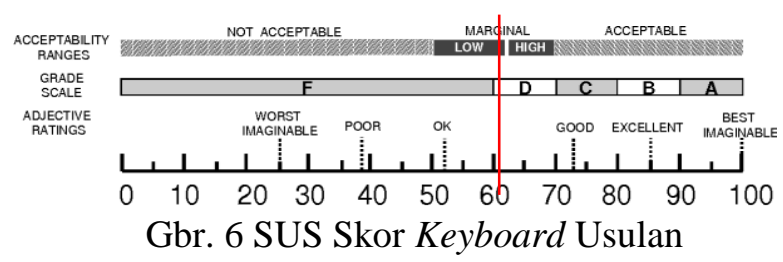

Berdasarkan perhitungan, Acceptability Ranges masuk kedalam kaetgori low, Grade Scale terkategori D, dan Adjective Rating terkategori $O k$. 


\section{KESIMPULAN}

Berdasarkan penelitian yang dilakukan, skor usability keyboard qwerty adalah senilai 54.16. Berdasarkan perhitungan, Acceptability Ranges masuk kedalam kaetgori low, Grade Scale terkategori F, dan Adjective Rating terkategori Ok. Perancangan ulang interface keyboard dilakukan dengan metode focus group discussion. Terdapat dua ide perbaikan yaitu penyesuaian dimensi keyboard dengan panjang antropometri ibu jari dan penyusunan kembali susunan huruf didasarkan intensitas penggunaan huruf. Pengukuran usability keyboard usulan adalah senilai 60.20. Berdasarkan perhitungan, Acceptability Ranges masuk kedalam kaetgori low, Grade Scale terkategori D, dan Adjective Rating terkategori Ok. Terjadi peningkatan skor usability keyboard usulan dibandingkan keyboard qwerty sehingga dapat disimpulkan keyboard usulan lebih mudah digunakan dan diterima oleh sampel. Keyboard ini dapat digunakan sebagai model baru keyboard handphone. Perlu analisis lebih lanjut mengenai perbandingan tingkat efisiensi gerakan yang ditimbulkan dari jenis keyboard usulan dengan keyboard qwerty.

\section{REFERENSI}

[1] Annizar, M., Tirtayasa, K., Muliarta, I, M. (2017) Penambahan Alas Mesin dan Pemberian Peregangan Dinamis di Bagian Proses Pemotongan Singkong Menurunkan Beban Kerja, Keluhan Muskuloskeletal, dan Meningkatkan Produktivitas Kerja pada Industri Keripik Singkong, Jurnal Ergonomi Indonesia, 3, 29-38.

[2] Audi, M., Rokhmawatu, R, I., Az-zahra, H, M. (2018) Analisis Aspek Usability dan User Experience Website dan Aplikasi Mobile Radio Streaming (Studi Pada Website dan Aplikasi Mobile Radio Prambors), Jurnal Pengembangan Teknologi Informasi dan Ilmu Komputer, 2, 6361-6400.

[3] Fadhilah M R., dkk. (2016) Review Layout Keyboard yang Optimal untuk Pengetikan dalam Bahasa Indonesia. Prosiding Seminar Nasional Teknologi Informasi dan Multimedia, 97 - 102.

[4] Putri, D, K., Haq, A. (2005) Virtual Keyboard dalam Pendekatan Ergonomi, Proceeding of National Seminar on Human Aspect in Computer-Based System, Bandung, 21-25 September, 132-138.

[5] Rahadi, D, R. (2014) Pengukuran Usability Sistem Menggunakan Use Questionnaire pada Aplikasi Android, Jurnal Sistem Informasi, 6, 661-671.

[6] Sukma, F. P. (2009) Perancangan Ulang Website Teknik Industri Universitas Sebelas Maret dengan Memperhatikan Aspek Usabilitas Menggunakan Metode Focus Group Discussion. Skripsi Universitas Sebelas Maret.

[7] Yola, M., Gustiandi, A. (2018) Perancangan Ulang Website Teknik Industri Universitas Islam Negeri Sultan Syarif Kasim Riau dengan Memperhatikan Aspek Usabilitas Menggunakan Metode Waterfall, Jurnal Teknik Industri, 4, 109-117. 